\title{
Interview with Barry Bergdoll ${ }_{(B)}^{*}$
}

Interviewers**

Amanda Saba Ruggiero (A), Luis Michal (L)

\begin{abstract}
* Interview accomplished in november 2016, MoMA-New York. Barry Bergdoll is Meyer Schapiro Professor of art history in the Department of Art History and Archaeology at Columbia University and curator at the Museum of Modern Art, New York.

\footnotetext{
${ }^{* *}$ Amanda Saba Ruggiero is architect, postdoctoral researcher enrolled at Faculty of Architecture and Urbanism - University of São Paulo, Brazil; Luis Michal is architect, currently enrolled in the Masters Program at Technische Universität München, Germany.
}

L: We want to talk about curating architecture as you are both a curator as well teaching architectural history. Could you talk about how you became a curator for architecture?

B: By accident! When I was a doctoral student at Columbia, we're talking about the early 1980s, it was also the time when there was a group of new architecture museums being formed, the Canadian Center of Architecture (CCA), the Deutsches Architekturmuseum, Netherlands Architecture Institute (NAI) in Rotterdam; these were also the years when the Musée d'Orsay was new in Paris and it had an architecture department. So there was a great interest in museums which happened also to coincide with Postmodernism, for better or worse, and in having museum exhibitions about architecture. I met Phyllis Lambert (A/N: founder of the CCA) while I was still a graduate student, and she asked if I wanted to come work for her at the CCA. In the end I didn't take the job but I ended up doing exhibitions for this relatively young and innovative institution. Right at the moment when they were opening their new building I did the second exhibition for the new museum in Montreal. My interests were archival, finding original documents and to find a way to exhibiting those documents so I ended up doing exhibitions in parallel with writing books and found myself with a parallel career, but being a full time curator was never an idea I had in my mind ahead of time.

A: How did you finally get to MoMA?

B: I first came to MoMA as a guest curator when Terence Riley was here $(\mathrm{A} / \mathrm{N}$ : director of the Architecture and Design Department, MoMA 1991-2005) to work on the Mies exhibition (A/D: Mies in Berlin, MoMA, 2001) which later went to Berlin, Barcelona and London. That was my previous experience with MoMA, so I had been there earlier as a guest curator for two years when Terence Riley stepped down. At that 
time the museum director asked for my ideas and then if I was interested myself in taking over the department.

L: The term "curating" has become increasingly popular in recent years, both in everyday culture as well as a profession for example with "star-curators". What do you think are the reasons for this shift of importance? And what does "curating" mean to you?

B: Well, I agree with you. I even wrote a little piece about this in Artpaper where they invited people to pick a word that they thought was overused and so I wrote a piece on the verb "to curate" which hasn't been a verb in English until recently. I think it's hard to diagnose the phenomena exactly why this is happening, I think it partly has to do with the culture of sampling and the culture of picking things. Now, to curate something really has become completely banal as a general term which just means to make choices, so by making a list of something, I have curated something. What it means to me, the one thing that I do think is interesting about the term that it's entirely connected with the making of events and the making of very public displays, so it has to do with the public persona of the curator. Whereas the origins of the word "curator" go back to somebody who took care of things, so they had much more to do with the idea of the permanent collection and the task of taking care of things, preserving them for future generations. So, historically the curator was a person in the background, not a person in the foreground. This moving of the curator to the foreground of course is not all bad, it means more admiration for the work curators do, on the other hand, I don't believe that curating is about curators. I believe it is about artists, ideas, history, the present moment, whatever it is, it is ABOUT something. For me to curate is partly to, indeed to create selections of things and to organize them in such a way that a public can engage with them in a meaningful way but it doesn't mean to put yourself out front.

L: You are a professional curator to say so. What would you consider your main competencies? And what are the tools you are working with?

A: Do you have a method?

B: I don 't know if I have a method, I have a toolkit maybe more than a method. I have often said that an architecture curator is quite different from an art curator for the obvious reasons that are often discussed. Architecture collections are not collections of buildings, they are collections of things that represent architecture like drawings, photographs, films, whatever records the activity of designing buildings or public spaces may be. Therefore, contrary a little bit to what I just said, namely that the curator should not be too present, the architecture curator in my view, is someone who needs to very self-consciously create an installation, that creates an atmosphere for thinking about the things that have been brought together. Those things tend to be very hybrid and of different natures and they tend also not to be things that are meant to be looked at as direct contemplative experience, like a painting or a sculpture. I do have some techniques that I tend to use over and over again, but I think that the main method is, in order to display architecture you have to create an architecture. There is a curatorial architecture in a way that there is no necessarily with a painting or a sculpture or a photography exhibition. 
L: What skills do you bring to this ambition to create a "curatorial architecture"?

B: I am trained as an architectural historian, so I have a considerable knowledge of the history of architecture and I have great passion for architecture. And I am also a teacher, so I have a great passion for trying to convey that passion to other people. Now, a teacher generally does it by talking or getting other people to discuss, through all the things that we know take place in a classroom. A curator has to figure out how to have a similar sharing of passion, when he or she is not present. I don't know if I am talented in it, but what I like to do, is think about how to arrange things in space in such a way that people will engage with them. I have often said, what I think is so fascinating about being a curator of architecture is that it is half way between the position of being an historian scholar and being an architect. It's the closest that a non-architect comes to actually making architecture and you make an argument through the deployment of things in space. It is the perfect mid-way point between teaching or writing and making architecture which is why I enjoy it so much.

A: Are there any particular shows, persons, curators or historians in the field of curating who have influenced your work as a curator?

B: That's a great question, I am trying to think. I must say that when I first started doing this in the late 1]980s, in Montreal and Paris one didn't talk about curators in the same way then, so I didn't really think of other curators the way you might say. Many of my exhibitions involve the creation of some full-scale environments and they often involve the deployment of film in the gallery space as a way of engaging people, but I am not quite sure where that comes from. I suppose it is not particularly copying somebody else but the experience of working with certain people, particularly working with Terry Riley on "Mies in Berlin" and the conversations that we had about it. Another thing that I should have said earlier is that making an exhibition is a highly collaborative process with sorts of teams and all sorts of expertise, partly infrastructure at MoMA. It is really like getting a building together, you need the construction team, you need the construction manager, you need the plumbers, you need the concrete people, there are installation teams, there are photographers, those are people that have to come together to create this thing called the exhibition. I don't think that there is one person who I want to be like or I want to make an exhibition like that person's exhibitions. I guess different curators do have different styles and I suppose I have a certain type of style or certain type of scenography that appears and appeals to me. I have done exhibitions that are quite different from one another, it is not a standard set of parts each time.

L: That leads us to the next question: How do you choose your topics? Which audiences do you want to reach?

B: First of all I would like to add maybe as a bridge between the last question and the new question, I also think that each exhibition demands its own design. So, you're going to figure out in relationship to the subject matter which tools you use and which tools that lend themselves to making a public experience for a particular subject. I like to think that in the 10 years I have been at MoMA that I have had different strains of exhibitions, some are what I call the "activist exhibitions" where I invite people to think about solving a problem. When we start out together we don't even know 
what's going to be produced or how it's going to be designed. Another part has to do with taking extremely large chapters in the history of architecture and either asking new questions about them or trying to insert them more into the mainstream. That was the case for example with "Latin America in Construction" (A/N: MoMA 2015) since architectural history education in the United States has tended to be about the US and Europe and has often omitted vast other territories of the world so I wanted to set out to correct that. Other times it's very simple, for example, I thought Henri Labrouste is one of the great architects of modernity and one of the great architects of the 19th century and each generation has a different take on him and thought my take is different from previous ones so, I am going to put it out there (A/N: Henri Labrouste: Structure brought to Light, MoMA 2013). And then as luck would have it, we were able to time it with the big controversy over the future of the New York library in 2013, so there was a dialogue with this contemporary issue.

A: Could you elaborate on both projects which you would consider as great successes as well failures of yours?

B: Yes, I am interested in failure, I think if you don't have failure then you haven't taken any chances, any risks. So we could just take two examples among the activist exhibitions. I think that the exhibition "Rising Currents" was an enormous success because it worked at many different levels. It engaged a general public in thinking about the city and climate change and about the ways in which architects and designers, landscape designers might be able to actually bring positive things to a very frightening problem. At the same time, it intrigued the city administration and actually had some impact on policies and helped lead to federal government programs dealing with coastal resilience. So it was an exhibition that went from the general public to parts of the United States government and lots of places in between academically.

The next exhibition in that series Foreclosed I don't think was a success at all, although it was successful for some of the individuals who worked on it and created interesting projects. However from the very beginning it was not a very good match between what I thought the exhibition was setting out to do, and what my collaborator thought it was about. I think there was a built-in tension in the exhibition that played out right the way through the projects through the presentation, it was less clear to me what it was about and what its impact was.

L: In recent years the world of architecture exhibitions has dramatically expanded both in terms of quantity as well with a great variety of formats like biennals or triennals taking place all over the world. What do you think is the role of MoMA in the contemporary and future field of architecture exhibitions?

B: Of all the places that you mentioned MoMA is the only place on that list where we can be absolutely sure that, people who never thought when they got up in the morning that they were going to an architecture exhibition might actually end up going to one. Because they come here to see a Picasso or they come here just because it has five stars in the guidebook. They end up in an architecture exhibition and if its well enough designed they suddenly find they're looking at something they didn't even know they were interested in. All of the same things can happen in a biennale, but you have to decide you're going to go there. So one of the problems with biennals 
and this might be inaccurate, but it seems to me that they are largely talking to people who are already interested in the topic even though they are much more spectacular events. And then you have the other smaller venues or in professional societies or schools of architecture. There might be great exhibitions, there might be wonderful new ideas, there might be great work on display, they might be beautifully designed, but I don't think they have a very good chance of attracting an audience who is not already interested. Because most people do not know that they are interested in architecture even though they really know when they hit something that's badly designed or they have a terribly designed public space or hideous new building goes up next to them they know it. Even though architecture is a thing that most impacts them, of all the things that are on display here at MoMA it has the hardest time getting people to come and look at. So, at MoMA you have got this unbelievable chance to attract a wider audience. On the other hand, there is the possibility that an local biennal might work locally so maybe people in Oslo have a debate about something that happens in Oslo.

A: What do you like about working within MoMA and what would you like to do rather differently?

B: As I mentioned earlier there is a built-in audience here; so that is one of the great things about MoMA. There also is just an unbelievable professional staff for getting things done and it's a bureaucracy with everything that is great and everything that's bad about a bureaucracy. There is an immense amount of talent and skill and there is an infrastructure to get things done. On the other hand sometimes there is a perfectionism here that makes you crazy. I suppose one of the biggest problems at MoMA is that because it has become such a complex, large organization, it's relatively difficult to do things here spontaneously or on short notice. If you are interested into finding something that would be of great actuality in the current environment, in most cases you can't possible see it through for two, three or four years and there is no guarantee that four years of now is really the right time to do it. So it is very hard to get the timing right given that schedule. Architecture galleries like the Storefront for Art and Architecture can do something like that, they can change the program and make something in six weeks from now. On the other hand if you ask anybody outside the architecture world what they think of this particular show they are going to ask you "what is it"?

L: Talking about institutions and their specific potentials as well limitations, do you have any dream projects which you would like to realize one day?

B: Tons... (laughs) I have a million ideas I won't have time to do. For an example I want to do an exhibition on the evolution of the physical model in architecture from 1821 to the present. 1821 is the invention of lithography, so lithography and then photography, so what does it mean to make a model in the period when there are replicable things for imaging. There have been previous, spectacular exhibitions that have been as important for exciting the general public as they have been for advancing scholarship like an exhibition on renaissance architecture models and there was one on baroque architecture models and both of those exhibitions were about the relationship between drawing and making three-dimensional, physical models. I want to make the big adventure from the middle-/early 19th century to how does the model work in a world in which technologies are changing so rapidly so that even the drawing itself is left behind. So that is one dream project. 
L: One last question, which advice can you give young people interested in making exhibitions on architecture?

B: Now there are all these master degree programs in curating architecture and I am not sure how I feel about them. You asked me at the beginning how I trained as a curator, I didn't train as a curator, there was no such as being trained as a curator. I am an architectural historian and one great thing about it is that I can write a book, I can give a lecture, I can give a walking tour in the city, I can make an exhibition, there are many different ways in which I can work with, both for myself organizing and thinking about architecture. I don't think that the exhibition is something that you do after you have already figured out something, it is also a way of thinking about architecture, a way of communicating architecture, a way of having a public. Your last question was about the ideas that you really would still like to do. Ask that to somebody who comes out of a curatorial program in which they have been studying curator techniques and have been studying other people's exhibitions, what are the 100 most important things that you would like to think about in architecture? I think the main advice is to develop a passion for the subject and remember that an exhibition is a medium, it is not in the end in itself.

A+L: Gladly we're both architecture students (laughing). Thank you very much for the interview! 